Document downloaded from:

http://hdl.handle.net/10251/102175

This paper must be cited as:

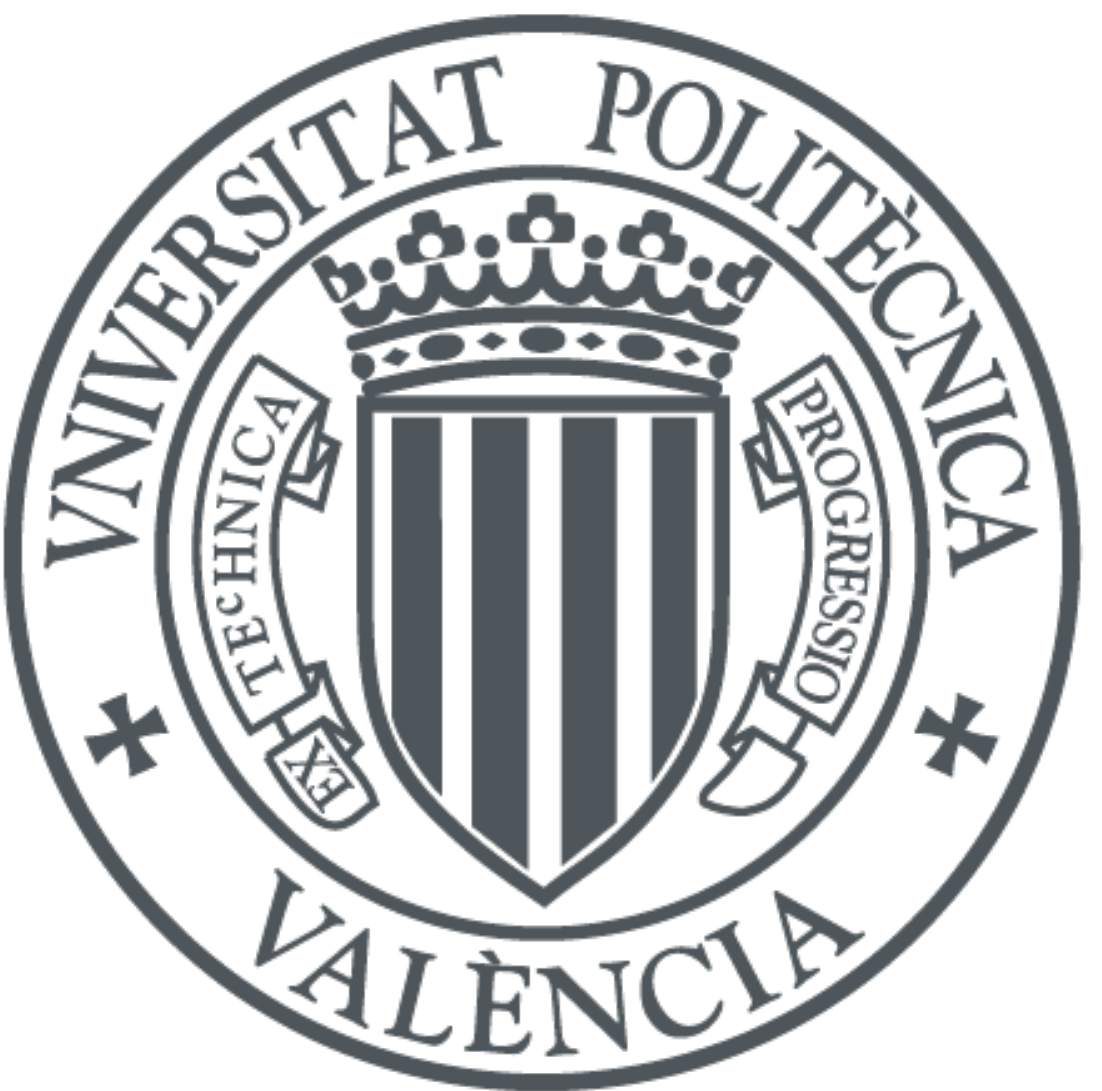

The final publication is available at

https://doi.org/10.1177/1468087417693078

Copyright SAGE Publications

Additional Information 


\title{
Effect of In-Cylinder Swirl on Engine Efficiency and Heat Rejection in a Light- Duty Diesel Engine
}

\author{
P. Olmeda ${ }^{1}$, J. Martín $^{1}$, D. Blanco-Cavero ${ }^{1}$, A. Warey ${ }^{2}$ and V. \\ Domenech $^{2}$
}

${ }^{1} \mathrm{CMT}$ - Motores Térmicos. Universitat Politècnica de València. Camino de Vera s/n, 46022 Valencia, Spain.

E-mail: $\quad$ jaimardi@mot.upv.es

Telephone: $\quad+(34) 963877650$

Fax: $\quad+(34) 963877659$

${ }^{2}$ General Motors Global R \& D. USA

E-mail: alok.warey@gm.com

Telephone: +(586) 5639703

Fax: $+(248) 8571163$

\begin{abstract}
During last years, the growing awareness about the impacts of climate change is leading to an increase in the importance of the efficiency over other criteria in the design of internal combustion engines. In this framework, the heat transfer to the combustion chamber walls can be considered as one of the main sources of indicated efficiency diminution. Hence, the main objective of the current research is to thoroughly assess the effect of the swirl ratio (SR) on the heat rejection to the chamber walls, and thus on the efficiency, of a fully instrumented 4cylinder direct-injection Diesel engine with variable SR (covering the range from 1.4 to 3). The analysis, based on the engine Global Energy Balance, includes a combination of theoretical and experimental tools such as thermal flows measurement and dedicated thermocouples in the cylinder-head and liner. Considering the results, it is shown that an increase in swirl ratio leads to a heat transfer enhancement, along with important changes on the combustion development. As a result of the combination of these two effects, it is shown that intermediate swirl ratios can slightly improve engine efficiency at low load, while increasing swirl worsens the combustion process and efficiency at high load. On the other hand, convective heat transfer increases about 3\% of the fuel energy in the chamber when SR increases from 1.4 to 3 . The heat rejection characterization is completed with the analysis of the wall temperatures. In spite of the observed trends, heat transfer does not seem to be the only key issue for explaining the indicated and brake efficiencies, thus the pumping work plays an important role due to the effect of reducing the intake section to generate the swirl motion.
\end{abstract}




\section{Notation}

aTDC After Top Dead Center

CFD Computational Fluid Dynamics

GEB Global Energy Balance

$\dot{H}_{\mathrm{g}} \quad$ Exhaust gases enthalpy

HT Heat transfer

$\mathrm{H}_{\mathrm{v}} \quad$ Lower Heating Value

$\mathrm{m}_{\mathrm{f}}, \dot{m}_{\mathrm{f}} \quad$ Fuel mass / fuel mass flow

$\mathrm{N}_{\mathrm{a}} \quad$ Power to run the auxiliaries

$\mathrm{N}_{\mathrm{b}} \quad$ Brake power

$\mathrm{N}_{\text {fr }} \quad$ Friction power

$\mathrm{N}_{\mathrm{i}} \quad$ Gross indicated power

$\mathrm{N}_{\mathrm{p}} \quad$ Pumping power

$\dot{Q}_{\mathrm{a}} \quad$ Heat rejection in the intercooler

$\dot{Q}_{\text {cool }}$ Heat rejection to coolant

$\dot{Q}_{\text {misc }} \quad$ Miscellanea heat term

$\mathrm{Q}_{\text {rad }}$ Heat radiation

$\dot{Q}_{\text {oil }} \quad$ Heat rejection to oil

RoHR Rate of Heat Release

SoE Start of Energizing time

SR Swirl Ratio

t Time

T Temperature

TDC Top Dead Center

VGT Variable-Geometry Turbocharger 


\section{Introduction}

Concerns about the efficient use of the available energy resources have been a major issue for a long time, acquiring a central role after the energy crisis of the seventies. Along with this motivation which led to big instability in the energy supply and a high increase in fuel prices, new ones have appeared in recent years. Nowadays environmental concerns are widespread mainly due to two types of environmental problems arising from intensive use of fossil fuels: global scale effects (i.e. climate change) and local scale effects (i.e. poor air quality in cities). The combination of these aspects leads to scenarios with increasingly high fuel prices and stricter rules for its use, which directly affects the automotive industry. As the internal combustion engines dominate the automotive market, the efforts to raise their efficiency have been continuous. The research goes from the studies on new fuels [1] to improvements on engine subsystems as: new injection strategies [2,3], improvements in turbocharger models [4], new combustion modes [5], new thermal management strategies [6], etc.

Most of the research in these engines is related to the understanding of the processes inside the combustion chamber [7], being one of the most important the air motion in the chamber, since it is a key issue to improve the air-fuel mixing process and achieve faster burning rates. That is one of the reasons why modern Diesel engines are designed to generate vorticity in the chamber (swirl motion) that leads to enhanced turbulence during the combustion development, thus affecting emissions and consumption. On the other hand, this air motion leads to higher heat transfer (HT) between the gas and the surrounding walls, leading to a decrease in the efficiency and therefore to a higher fuel consumption. Besides, these mentioned effects depend on other engine parameters as load, which makes it difficult to obtain the best trade-off between air motion and fuel consumption.

There are several experimental and modeling studies which try to explain the main effects of this air motion due to swirl on combustion processes in Diesel engines, but none of the studies try to solve this problem from a wider point of view. They usually focus on the study of the air motion and its effect on the combustion process but not on the effect on other key issues such as heat transfer, efficiency or Global Energy Balance (GEB).

In this paper the effect of Swirl Ratio on different engine parameters (from a general point of view up to more specific ones) is analyzed in a comprehensive way. In this way, not only the effect on fuel consumption is given but also the effect on the global energy balance, i.e. how the fuel energy is divided, on brake and indicated efficiencies, on the Rate of Heat Release (RoHR) and on heat transfer.

\section{Methodology}

The objective of this work is the assessment of the swirl effect on heat rejection to the chamber walls and hence on engine efficiency, by means of the theoretical and 
experimental analysis of the Global Energy Balance. The methodology followed is summarized in Figure 1. The work was structured in three main parts, as explained in the next paragraphs:

- A calibration of different models to reproduce internal sub-systems was initially performed. It includes heat transfer (convective model and a lumped conductance model) and mechanical losses model, along with some engine uncertainties. This was done using data from both motoring and combustion tests, using as main input the information of in-cylinder pressure, experimental wall temperature measurements, some fluid (coolant and oil) temperatures, and mass flows (for the sake of brevity the details have been omitted).

- Once the models were tuned, the experimental swirl sweep studies were carried out, in the installation described below, at two operating points with different loads at $2000 \mathrm{rpm}$. For each operating point, the tuned models were used to calculate the different energy terms of the internal energy balance, in which the in-cylinder pressure was the main input to calculate the gas evolution, used by the heat transfer models to obtain the heat flow and the wall temperatures, along with the split of mechanical losses.

- Finally, the information of the experimental HT obtained from the fluid flows and temperatures was used to complete the analysis from the external approach, thus validating the internal prediction done with the models.

As a result, a complete description of the effect of swirl ratio (SR) on the efficiency and the energy split was carried out, taking into account all the relevant energy transformations and thermal processes in a DI Diesel engine.

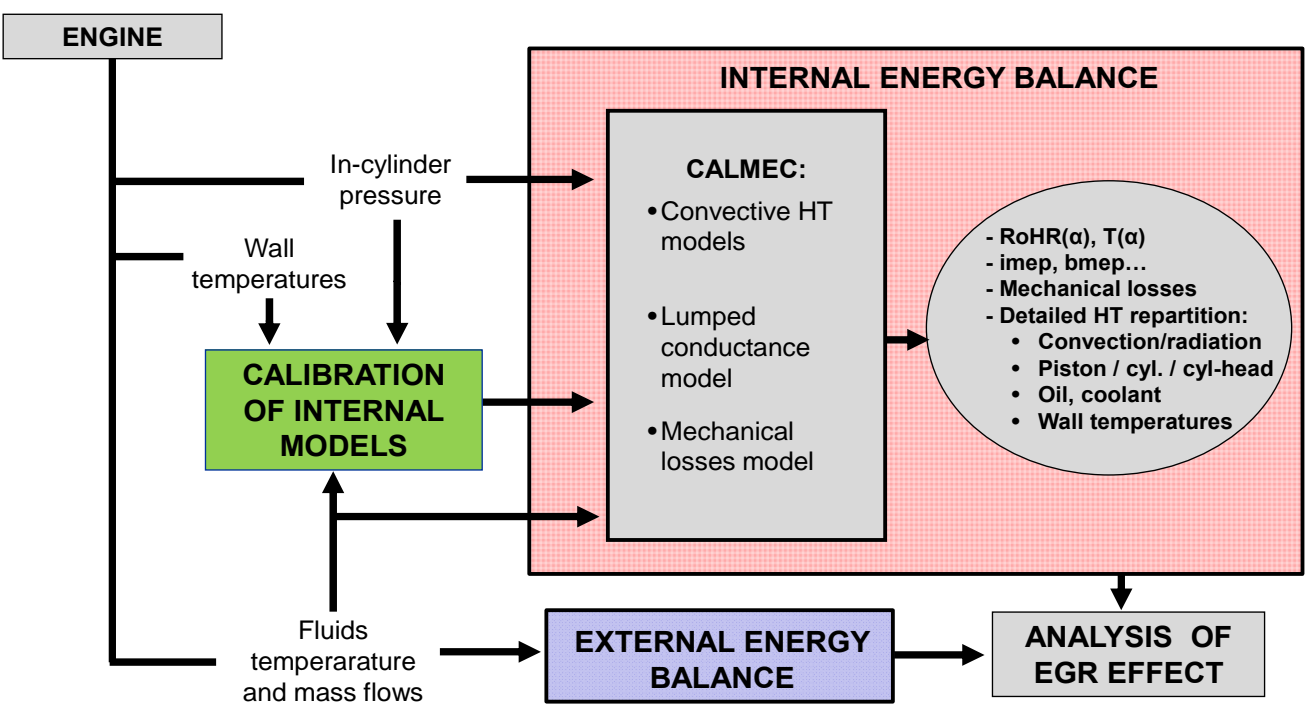

Figure 1. Methodology

\subsection{Models and uncertainties calibration}

An initial adjustment was carried out to ensure the accurate estimation of the heat transfer to different engine parts, where special attention was paid to the heat rejection in 
the combustion chamber. Thus, tests in motored conditions were used to adjust some uncertainties (real compression ratio, TDC position and the constant of a deformation model) along with the constants of the Woschni-like equation velocity term, $\mathrm{C}_{\mathrm{W} 1}$ and $\mathrm{C}_{\mathrm{W} 2}$. The tuning process is based on the application of the first law of thermodynamics to obtain the RoHR residuals (they should be zero because no fuel is injected). More details of the process can be found in [8].

The geometry of the lumped conductance model nodes [9] was adjusted to fit the real engine geometry and to facilitate the comparison between experimental and modeled nodes temperatures. The lumped model is included in CALMEC, an in-house developed $0 \mathrm{D}$ combustion diagnosis tool briefly described in section 3.2. The experimental temperatures obtained with the thermocouples were used to validate the results provided by the lumped conductance model, obtaining an average error about $5^{\circ} \mathrm{C}$ and a maximum error lower than $10^{\circ} \mathrm{C}$ in most cases. The mechanical losses model [10] was adjusted using experimental measurements of indicated and brake power.

\subsection{Global Energy Balance}

For the external approach, the engine was considered as a black box with some energy flows entering and some others leaving it. Since these flows are external, they can be directly measured, and used for the validation and completion of the internal analysis, which was mainly based on theoretical models. The terms included in the external GEB are thoroughly explained in [11].

Unlike the terms involved in the external GEB, those related to the internal GEB cannot be easily measured, except the indicated power that can be obtained from in-cylinder pressure. Thus, to obtain an accurate estimation of the rest of terms, several submodels [8] were necessary in combination with the available experimental in-cylinder pressure. As stated, these submodels are included in CALMEC. These terms are also thoroughly explained in [11].

\section{Experimental and theoretical tools}

\subsection{Experimental setup}

\subsubsection{Light-Duty Diesel engine}

A production GM 1.9L Diesel engine was used in this research. The 4-cylinder engine uses a Common-Rail fuel injection system and a variable geometry turbocharger (VGT). The engine has four valves per cylinder, centrally located injectors and a re-entrant type combustion chamber. The SR can be varied from 1.4 up to 3 by changing the position of a swirl flap. All relevant engine data are given in Table 1. The engine was set up to meet EURO IV emissions regulations.

Table 1. Engine and injection system specifications 


\begin{tabular}{|l|l|}
\hline Engine Type & DI, 4-cylinder, 4-stroke \\
\hline Displaced volume [cm3] & 1900 \\
\hline Stroke [mm] & 90.4 \\
\hline Bore [mm] & 82 \\
\hline Combustion Chamber & Re-entrant type \\
\hline Compression ratio & $17.5: 1$ \\
\hline Max. Power [kW] @ speed [rpm] & 110 @ 4000 \\
\hline Max. Torque [Nm] @ speed [rpm] & 315 @ 2000 \\
\hline Injection System & Bosch Common Rail (solenoid) \\
\hline
\end{tabular}

\subsubsection{Test cell instrumentation}

The most relevant instrumentation of the test cell is presented in Table 2 while the schema of the test cell can be seen in Figure 2. The engine was directly coupled to an electric dynamometer that allowed controlling the engine speed and load. The installation also included complete instrumentation to measure different gas temperatures, pressures and mass flows, and liquids mass flows and temperatures.

Table 2. Test cell instrumentation

\begin{tabular}{|l|l|l|}
\hline Variables Measured & Sensors & Range \\
\hline Liquids T (coolant, oil, cooling water at exchangers...) & Resistance thermometers (PT100) & $-30-350{ }^{\circ} \mathrm{C}$ \\
\hline Gases T (inlet and exhaust lines, EGR...) & K-type Thermocouples & $-200-1250{ }^{\circ} \mathrm{C}$ \\
\hline Metal T (see section 3.1.4) & K-type Thermocouples & $-200-1250{ }^{\circ} \mathrm{C}$ \\
\hline Fuel mass flow & AVL 733s.18 & $0-41.67 \mathrm{~g} / \mathrm{s}$ \\
\hline Air mass flow & AVL Flowsonix Air & $0-1400 \mathrm{~kg} / \mathrm{h}$ \\
\hline Coolant Flow & DN25 Flow meter & $8.8-350 \mathrm{l} / \mathrm{min}$ \\
\hline Torque & Dynamometer & $0-500 \mathrm{Nm}$ \\
\hline In-cylinder pressure & Kistler 6125C10 & $0-300 \mathrm{bar}$ \\
\hline
\end{tabular}

Liquids temperatures were measured with resistance thermometers, which are more accurate than the thermocouples used to measure gas temperatures. Furthermore, 88 thermocouples were installed at different locations in the engine block and cylinder-head in order to provide information regarding metal temperatures for the commissioning and validation of the lumped conductance model.

In-cylinder pressure was measured in each cylinder with Kistler $6125 \mathrm{C} 10$ glow-plug piezoelectric transducers and Kistler 4603B10 charge amplifiers. A crank angle increment of $0.5^{\circ}$ was used for the in-cylinder pressure acquisition, which was performed with a commercial control and acquisition system DRIVVEN. Mean variables were 
acquired at a low sample frequency of $100 \mathrm{~Hz}$ using SAMARUC, a CMT-developed test system that collects the signals of different sensors and controls the electric dynamometer [12].

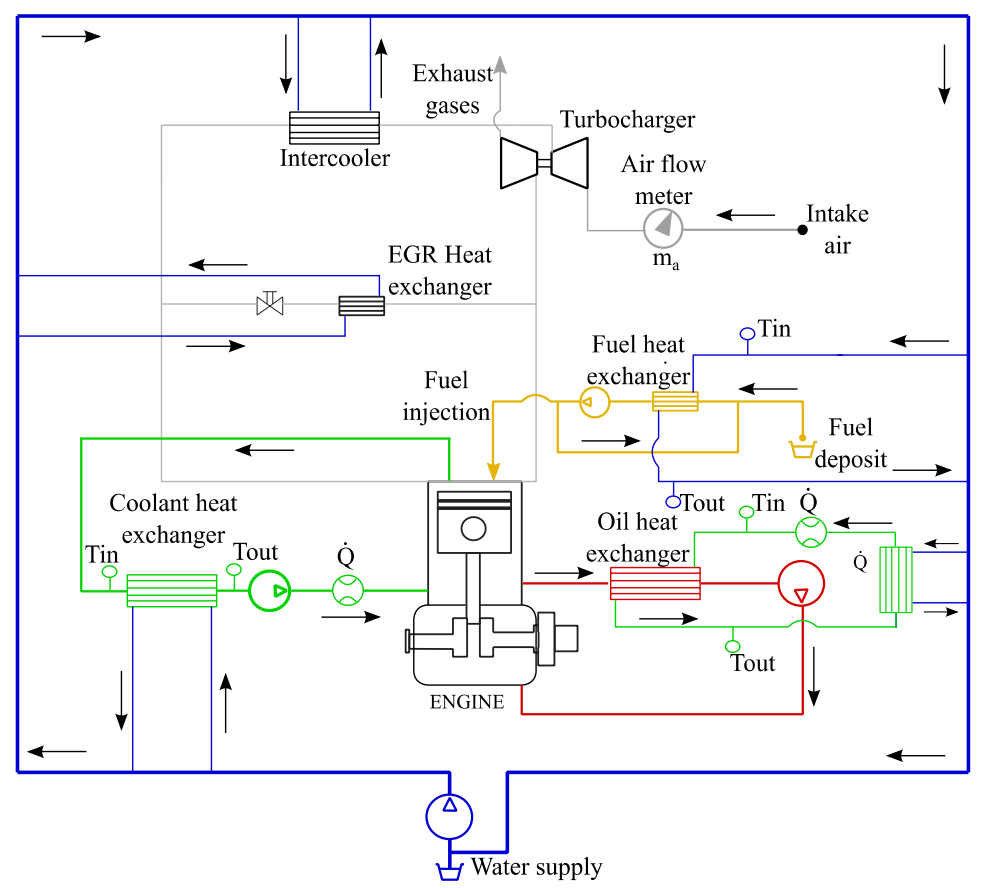

Figure 2. Experimental installation

\subsubsection{Instrumentation for wall temperature measurement}

As stated, engine cylinder-head and liner were instrumented with $88 \mathrm{~K}$-type thermocouples. 54 of them were installed in the cylinder head, distributed on two sections perpendicular to the cylinder axis and located $4 \mathrm{~mm}$ and $7 \mathrm{~mm}$ above the firedeck. The other 34 thermocouples were installed in the cylinder liner, at $1.3 \mathrm{~mm}$ from the internal liner surface and different positions along the piston stroke. Thermocouples were inserted through holes drilled directly in the engine structure.

The locations of the thermocouples in one cylinder can be seen in Figure 3. In graph (a), distribution of thermocouples in the firedeck is shown. All thermocouples are located at the two stated planes (at $4 \mathrm{~mm}$ and $7 \mathrm{~mm}$ ) and both planes at each cylinder have the same thermocouples distribution. In the cylinder liner, thermocouples were arranged along a vertical line, as seen in Figure 3 (b). In each cylinder there are four vertical lines of thermocouples separated $90^{\circ}$ from each other. Not all lines had four thermocouples, and there are more of them close to cylinder top than near the bottom. Top area was considered more interesting because it has a longer exposure time to chamber gas. Signals from the thermocouples were acquired by two data-loggers. 


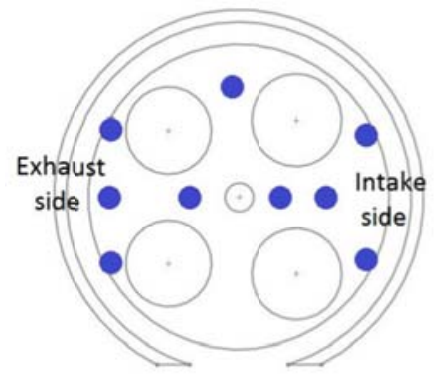

(a) Cylinder head

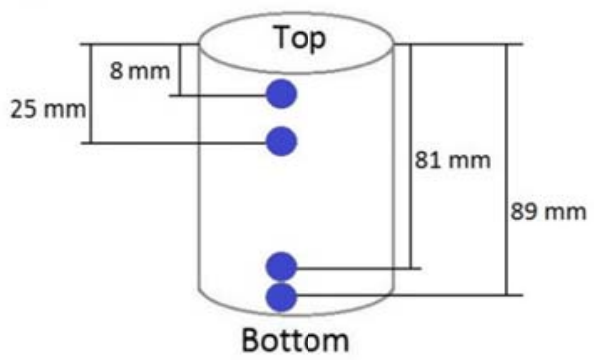

(b) Cylinder liner

Figure 3. Thermocouple distribution in the cylinder head (a) and in the liner (b)

\subsection{D model thermodynamic model (CALMEC)}

CALMEC [8] is the thermodynamic tool used to perform the combustion analysis; it calculates the instantaneous evolution of in-cylinder properties of the gas, and it models the internal energy terms. The model considers all the relevant engine subsystems through the combination of both physical and semi-empirical submodels $[8,13,14]$ to calculate the heat transfer to combustion chamber walls and ports, along with mechanical losses split. Main assumptions in this model are:

- Chamber pressure and temperature are assumed to be spatially uniform.

- Three species (air, fuel vapor and stoichiometric combustion products) are considered [15].

- Ideal gas law is used to calculate mean gas temperature.

- A filling and emptying model is used to calculate the trapped mass [16].

- Specific heat of the gas depends on both temperature and composition [17].

- Blow-by model is based on the evolution of the gas in an isentropic nozzle [16].

- Chamber volume deformation is calculated by means of a simple deformation model [14].

- Heat transfer to the chamber walls is calculated with a modified Woschni-like model [13].

A lumped conductance model was used to calculate wall temperatures in the chamber and ports along with the heat rejection to coolant and oil. The model consists of 102 nodes in the cylinder head, 66 in the liner, 10 in the piston and some boundary nodes that take into account the oil, coolant, fresh air, in-cylinder gas, and intake and exhaust gases. More details of this lumped model can be found in [7].

\section{Results and discussion}

In this section, the experimental and modeled results, along with the discussion regarding the swirl effect on energy balance and heat transfer is presented. Graphs show mostly experimental results, provided that they are available (external thermal flows and wall temperature). Modeled results will be discussed when experimental results are not available (heat transfer to the chamber walls). To assess the swirl effect, the study was 
carried out at two different operating points (k-points), as described in the next subsection.

\subsection{Engine operating conditions}

Two k-points were chosen as being representative of an NEDC emission homologation cycle. These k-points will be named using a composition of 2 figures: the first one is the engine speed (in rpm) while the second one is the bmep (in bar), thus having engine speed@bmep. Their most significant variables are shown in Table 3. As stated, they correspond to two almost extreme loads at $2000 \mathrm{rpm}$.

Swirl ratio was variated from 1.4 to 3 in 4 levels $(1.4 / 2 / 2.5 / 3)$. Hence, the complete test matrix is composed of ( 2 k-points) $x(4 \mathrm{SR}) \times 3$ repetition of each point.

Table 3: Main operating conditions k-points

\begin{tabular}{|c|c|c|c|c|c|c|c|c|c|}
\hline & $\begin{array}{l}\text { Speed } \\
\text { [rpm] }\end{array}$ & $\begin{array}{l}\text { bmep } \\
{[\mathrm{bar}]}\end{array}$ & $\begin{array}{l}\text { SR } \\
{[-]} \\
\end{array}$ & $\begin{array}{l}\text { Intake press. } \\
\text { [bar] }\end{array}$ & $\begin{array}{l}\text { Air mass } \\
{[\mathrm{g} / \mathrm{s}]}\end{array}$ & $\begin{array}{l}\text { EGR } \\
{[\%]}\end{array}$ & $\begin{array}{l}\text { Prail } \\
{[\mathrm{bar}]}\end{array}$ & $\begin{array}{l}\text { SoE } \\
\text { (Pil 1, Pil 2, Main) }\end{array}$ & $\begin{array}{l}\text { Fuel mass } \\
\text { (Pil 1, Pil 2, main) }\end{array}$ \\
\hline 2000@5 & 2000 & 5 & $1.4-3$ & $1.36-1.44$ & 44.0 & 0 & 650 & $\begin{array}{l}-20.4,-10.2,-1.2 /-22.1,- \\
13.1,-3.5\end{array}$ & $1.5,1.5,16.8$ \\
\hline 2000@20 & 2000 & 20 & $1.4-3$ & $2.29-2.46$ & 72.2 & 0 & 1250 & $\begin{array}{l}-22.7,-13.1,-3.5 /-22.9,- \\
13.3,-3.7\end{array}$ & $1.5,1.5,47.3$ \\
\hline
\end{tabular}

To isolate the effects of the swirl variation, all engine parameters except SR were kept constant. Therefore, swirl sweeps were performed with the same intake temperature $\left(45^{\circ} \mathrm{C}\right)$ and trapped mass at the IVC, as well as the same combustion phasing $\left(\mathrm{CA} 50=13^{\circ}\right.$ aTDC) and the injected fuel mass. Intake pressure was adjusted at each swirl level to get the same inlet mass flow. Furthermore, coolant $\left(85^{\circ} \mathrm{C}\right)$ and oil $\left(95^{\circ} \mathrm{C}\right)$ temperatures were kept constant in all the tests, thus avoiding interferences in the heat fluxes and friction losses when the swirl sweeps were performed.

With respect to the injection strategy, it consists of two pilots and one main injection. Pilot quantities $(1.5 \mathrm{mg})$ and dwell times $(0.8 \mathrm{~ms})$ were kept constant for all the points.

To ensure a stable thermal behavior of the engine, stabilization periods between 20 and 40 minutes were required. It was assumed that thermal stabilization was reached when the temperature variation rate of all the liquids (coolant, cooling water and oil) was lower than $1^{\circ} \mathrm{C} / \mathrm{min}$.

\subsection{External energy balance at low swirl conditions}

The analysis starts with the external energy balance of the two k-points with the lowest swirl ratio (1.4), used as reference points. Their energy split is shown in Figure 4, where the power of the different energy terms is plotted at the left hand, and their relative percentages of the total fuel energy at the right hand. The nomenclature of the different 
terms are the following: $\dot{N}_{b}$ is the brake power, $\dot{Q}_{c o o l}$ is the heat rejection to the coolant, $\dot{Q}_{o i l}$ is the heat rejection to the oil, $\dot{Q}_{a}$ is the heat rejection in the intercooler, $\dot{H}_{g}$ is the exhaust gases enthalpy, and $\dot{Q}_{\text {misc }}$ is a miscellanea term that is mainly composed by heat rejection to the ambient and the energy unbalance due to the experimental uncertainties. As shown at the left, the two k-points have very different values in power terms, being the fuel power $50 \mathrm{~kW}$ and $143 \mathrm{~kW}$ respectively.

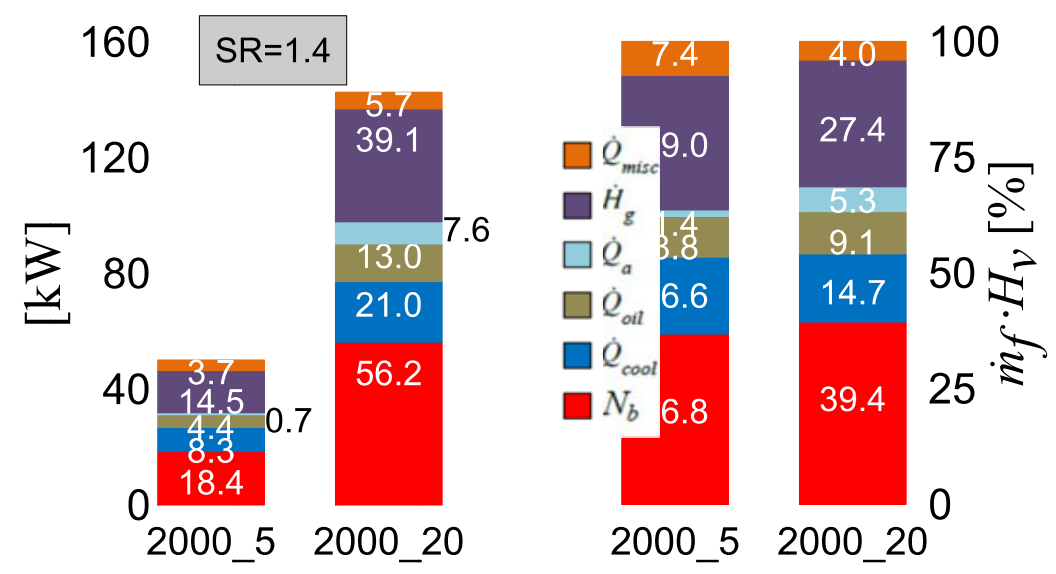

Figure 4. External energy balance with $\mathrm{SR}=1.4$

Change in injection and air management settings at different loads lead to important differences in the energy repartition. One of the most evident changes is the heat rejection reduction. Thus, in relative terms, the total heat transfer to coolant and oil decreases with load (25.4\% vs $23.8 \%)$. This trend is in agreement with the expected behavior: increasing the load leads to higher gas temperature in the chamber and thus, increasing the chamber heat rejection in almost 2.5 times. However, the higher load leads to a fuel power increase of about 2.85 times from bmep $=5$ bar to bmep $=20$ bar. Hence the relative importance of heat transfer diminishes by $3.5 \%$ of the fuel energy.

One of the consequences of the lower heat rejection in the chamber, along with the lower mechanical losses (in relative terms), is the higher brake efficiency at the high load kpoint in comparison with the lower load conditions (39.4\% vs 36.8\%), as usual in Diesel engines, where the maximum efficiency is usually located near the full load conditions.

The changes in the air management settings directly affect the heat transfer in the intercooler, which shows an important increase from $1.4 \%$ to $5.3 \%$ of the fuel energy. This is a direct consequence of the higher boost pressure reached at high load (2.29 bar vs 1.36 bar at low load). If exhaust gases sensible enthalpy is analyzed, despite of the higher exhaust temperature $\left(470^{\circ} \mathrm{C}\right.$ vs $\left.316^{\circ} \mathrm{C}\right)$ due to higher fuel-to-air ratio, combustion duration and the higher gas flow, it shows a reduction $(1.6 \%)$ when the load increases.

Finally, the miscellanea term tends to diminish with load, mainly due to the reduction of the heat rejection to ambient (both coolant and oil temperatures and thus block 
temperature were kept constant) and the lower experimental uncertainties when measuring and computing (using fluid flow rates and temperatures) the thermal flows.

Once the external energy balance has been discussed, the variation of the energy terms due to swirl changes will be evaluated, taking as reference the results at this low swirl. First, the brake efficiency term and the sub-terms affecting this parameter will be dealt with. Then, the focus will be put on the heat rejection issue, analyzing the heat loss to the different engine parts, completing the analysis with the study of the wall temperatures.

\subsection{Brake and indicated efficiency}

Figure 5 shows the variation of brake efficiency, along with the parameters affecting it, in the SR sweep of the 2 analyzed k-points. In the two cases, increasing swirl ratio led to a brake efficiency worsening at the highest swirl level $(-2.3 \%$ and $-5.1 \%$ at low and high load respectively). The trend with the SR is monotonous at high load while at2000@5 there is a maximum at the intermediate level $(\mathrm{SR}=2)$. Although the small difference with the reference SR $(<0.1 \%)$ can be affected by the experimental uncertainties, this trend has also been observed at other operating points at low engine speed (not included in this work for the sake of brevity) and it is also in agreement with the gross indicated efficiency $\left(\eta_{i}\right)$ which also shows a small increase at intermediate $S R=2$. Thus, it can be concluded that increasing swirl at low load up to a certain SR (2 in this case) can have a slightly positive effect on brake efficiency.

As Eq. (1) shows, brake power $\left(N_{b}\right)$ is the difference between gross indicated power $\left(N_{i}\right)$ and mechanical losses, i.e. pumping $\left(N_{p}\right)$, auxiliary $\left(N_{a}\right)$ and friction losses $\left(N_{f r}\right)$ and thus, its behavior can be analyzed taking into account these terms.

$$
N_{b}=N_{i}+N_{p}-N_{a}-N_{f r}
$$

Regarding the gross indicated efficiency, its qualitative trend is the same as observed in the brake efficiency, thus there is a progressive diminution of $\eta_{i}$ when swirl increases at high load (maximum variation of $-1.2 \%$ ) and also at low load (maximum variation of $0.4 \%$ ) for SR higher than 2 . The indicated efficiency changes can be explained taking into account the variation of the shape of the RoHR and the heat rejection to chamber walls described in the following sections. Thus, it seems that the HT increase at higher SR is compensated in the case of low load with the combustion enhancement at intermediate $\mathrm{SR}<2$, while at high load both HT increase and combustion worsening (see next section) reduces the gross indicated efficiency. 


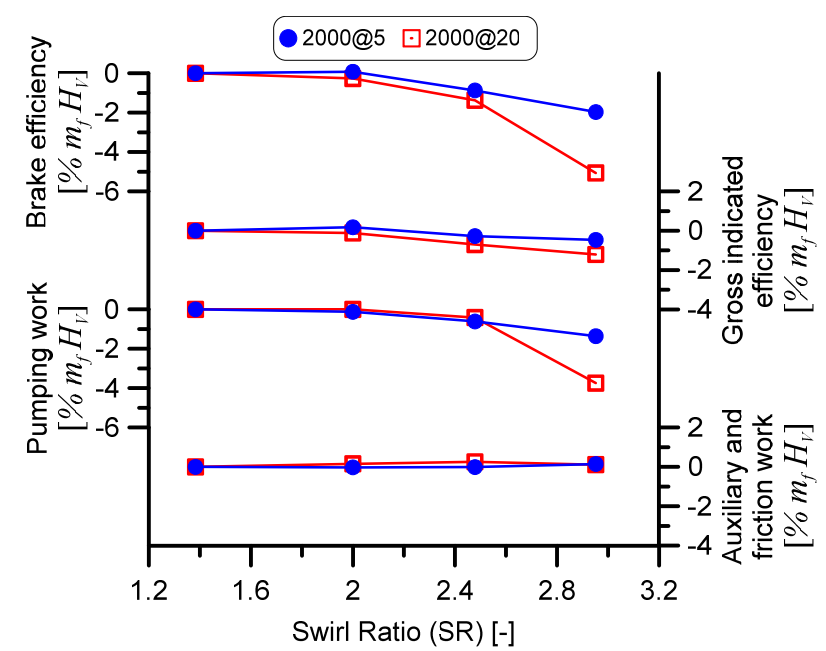

Figure 5. Variation of brake, indicated efficiency, pumping work and auxiliaries and friction losses

Contrary to the gross indicated and brake efficiencies, Figure 5 shows that pumping losses always increase continuously when SR gets higher. This can be explained taking into account that SR is modified by closing a valve located upstream of the helical port. This increases the restriction to the intake air flow, leading to a higher pressure drop. Hence, a more closed VGT position is required to reach the required boost pressure to maintain the same intake mass as when it is open $(\mathrm{SR}=1.4)$. As a consequence, pumping losses increases between $1.4 \%$ at low load and $3.7 \%$ at high load, thus becoming a key issue, especially at high load.

For the sake of brevity, auxiliary and friction losses have not been plotted separately but the sum of both terms remains almost constant when the swirl is modified. This behavior can be explained taking into account that auxiliary losses depend on fuel, coolant and oil pumps power [6], which do not change since the engine speed, injection pressure, coolant mass flow and oil pressure were kept con- stant. On the other hand, oil temperature was also maintained and no important effect on engine friction took place when swirl increased.

According to the analysis, it can be concluded that brake efficiency reduction at high SR were governed by gross indicated efficiency and pumping losses. Since both of them showed a negative behavior for SR higher than 2, the brake efficiency decreased in all the cases. For moderate swirl levels up to $\mathrm{SR}=2$, it was found that a small benefit can be obtained in both indicated and brake efficiency at low load, while the indicated efficiency deterioration and the higher pumping work diminishes continuously the brake efficiency when SR gets higher at high load.

\subsection{RoHR and in-cylinder pressure}

Figure 6 shows the temporal evolution of the simulated injection rate, the in-cylinder pressure and the RoHR for both operating conditions. In general, it is well-accepted that an increase in swirl ratio promotes a more efficient air fuel mixing by increasing the 
turbulent effects in the combustion chamber during the combustion process. In this sense, considering RoHR profiles in Figure 6 left (low load case), it is possible to state that the higher the swirl ratio, the higher the peak of RoHR as well as the sharper the slope of the main injection combustion profile. Nonetheless, when the engine load is increased the combustion scenario changes and the impact of a higher swirl ratio on RoHR is completely different.
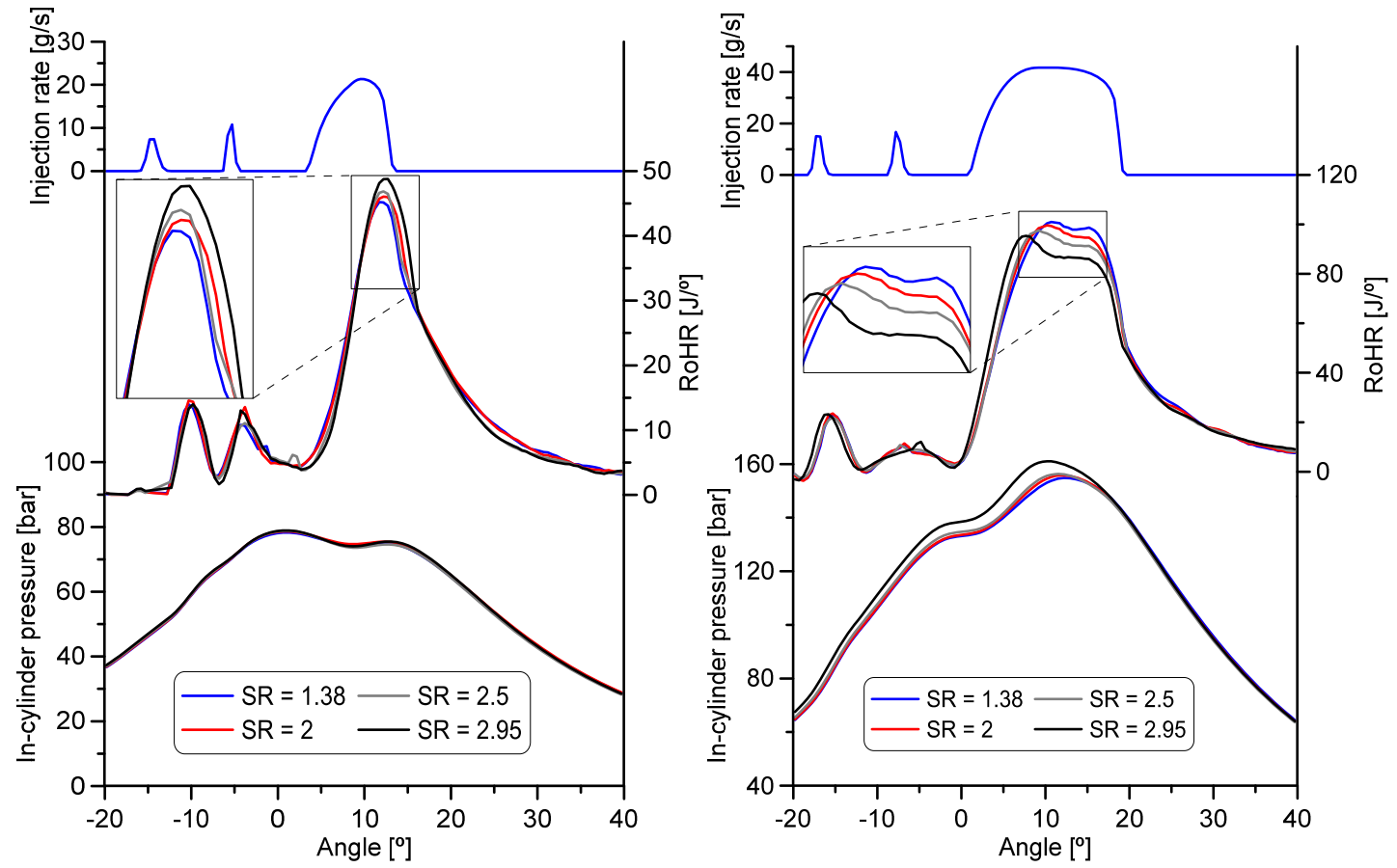

Figure 6. Temporal evolution of the simulated injection rate, the in-cylinder pressure and the RoHR at2000@5 (left) and 2000@20 (right)

An increase in engine load implies a larger injection process. In this sense, the high rotation air movement induced by high SR enhances the interaction between sprays which leads to a local enrichment of the air-fuel mixture and therefore a deteriorated combustion process [18]. In addition, de la Morena in [19] using CFD calculations in a similar engine platform, found that high SR push combustion process towards the squish region at high load, limiting the spray tip velocity and penetration. Thus, the spray is deflected towards the fire deck, preventing it from efficiently entraining fresh air in the piston bowl. These two mentioned phenomena can explain a lower RoHR peak when swirl ratio is increased at high load, as presented in Figure 6 right. In this sense, a higher SR implies larger combustion duration with larger CA90 and similar ignition delay as it is shown in the left part of Figure 7. It is worth to mention that no injection optimization was performed and thus, taking into account the interaction between injection and swirl, it is possible that this effect can be lower with a proper injection optimization, which is out of the scope of this paper. 

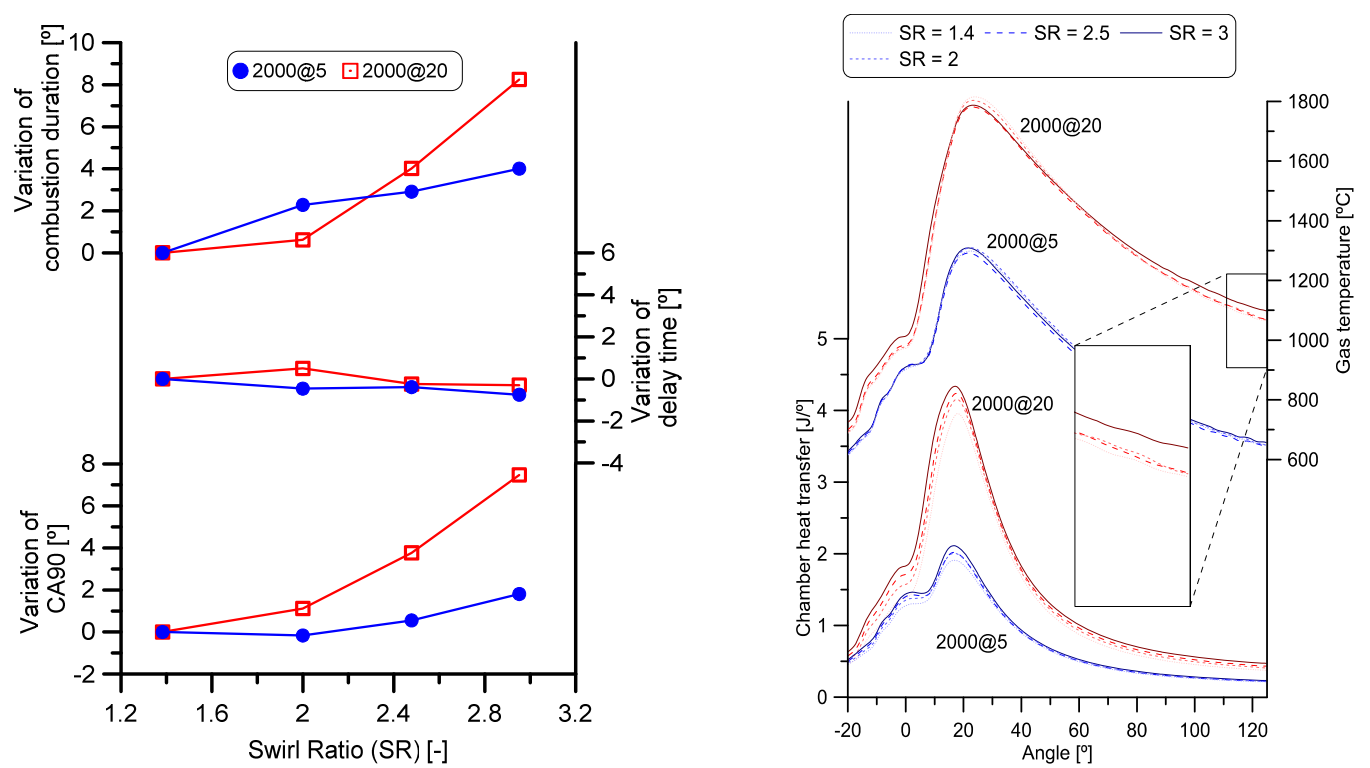

Figure 7. Variation of combustion duration, delay time and CA90 with swirl ratio (left) and modeled instantaneous heat transfer in the chamber and gas temperature (right)

\subsection{Heat transfer analysis}

As a consequence of the described trends of the RoHR and in-cylinder pressure, the gas temperature in the chamber is also affected by the swirl change (right part of Figure 7). Thus the global trend to enhance the combustion at low load leads to a slightly higher peak temperature while it diminishes at high load due to the combustion worsening. During the last part of the combustion and the expansion, temperatures do not show a clear trend at low load, and thus, the exhaust temperature at the turbine inlet changes less than $10^{\circ} \mathrm{C}$. However, the much longer duration at high load led to increasing temperature in the chamber at the end of the expansion when SR got higher. As a result the exhaust temperature increased in this case about $50^{\circ} \mathrm{C}$.

Apart from temperature, the big issue when SR increases is the change in the convective heat transfer. It increases due to the air velocity increment, leading to higher HT to the chamber walls in both analyzed operating conditions, as shown in the bottom-right part of the Figure 7. This effect can be clearly seen close to the heat rejection peak (about $15^{\circ}$ aTDC), where the effect of higher pressure and gas velocity is more evident.

In order to perform a detailed analysis of the heat flux split in the chamber, the modeled heat rejection to cylinder-head, cylinder liner and piston (based on the modified Woschni-like model of CALMEC) are shown in Figure 9. It can be observed that, all these heat transfer terms increased with swirl as a consequence of the higher air velocity and changes in temperature: about $0.8 \%$ of HT to cylinder and cylinder-head, $1.2 \%$ to the piston, obtaining no clear differences between both operating conditions. On the other hand, heat transfer to ports rose about $0.3 \%$ at low load and $1.3 \%$ at high load due to the stated changes in the combustion process and, thus, in exhaust temperature. 
Since changes in auxiliary and friction losses, responsible for a portion of the heat transfer to coolant and oil, were almost negligible, the variation in the modeled heat transfer terms should be translated to the external heat transfer terms experimentally measured. In order to crosscheck the modeled results with the experimental heat transfer, heat rejection to coolant and oil are presented in the right part ofFigure 8 , where it can be seen that both terms tend to increase when SR got higher.

Global behavior of experimental HT to coolant was similar for the two k-points: it went up about $2 \%$ if maximum and minimum SR are compared. This variation are in good agreement with the detailed HT split in the chamber described, thus coolant variation slightly higher than the addition of HT to cylinder-head, cylinder and ports.
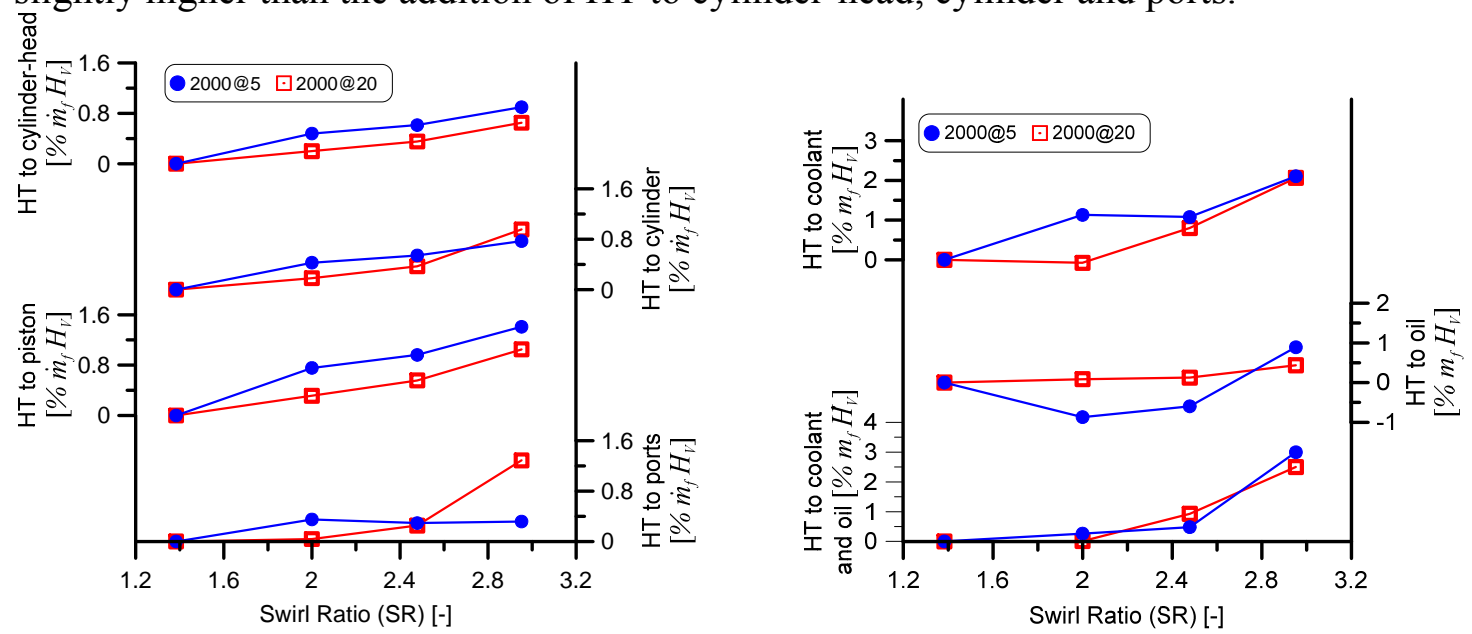

Figure 8. Variation of modeled heat transfer in chamber and ports with swirl ratio (left) and variation of experimental heat transfer to coolant and oil with swirl ratio (right)

Regarding HT to oil, a global trend to increase about $1 \%$ can be seen when extreme SR are analyzed. Main components of this term are friction, which hardly changed, and heat transfer to piston, that increases about 1\% of the fuel energy, as shown in Figure 9. At intermediate SR levels there is not a clear monotonous behavior, in particular at the low load operating conditions. As analyzed below, no evidence has been found to conclude that it is due to changes in the in-cylinder conditions and thus it is assumed that the experimental uncertainties become important in this case. It has to be taken into account that, although the whole analysis is being performed in relative terms with respect to fuel energy, the differences in experimental HT to the oil are close to $400 \mathrm{~W}$ at low load. This is one of the reasons to combine internal and external analysis in order to clarify some uncertain trends.

When the total HT to coolant and oil is analyzed, a clear increasing trend is obtained. Comparing modeled HT terms (left part of Figure 8) and experimental variations (right part of Figure 8), it can be concluded that they are in good agreement although the model slightly overestimated the effect of swirl on the HT (3.5\%-4\% vs $2.5 \%-3 \%)$.

\subsubsection{Wall temperatures}


The analysis of SR effect on heat transfer is completed analyzing the changes in local temperatures. For this purpose, two kind of analysis have been performed. On one hand, the effects of SR on a selected measured temperature in the liner and in the cylinder head are described. On the other hand, temperature maps were calculated through linear interpolation and extrapolation from the measured temperatures in both the liner and the cylinder head, thus allowing the spatial analysis.
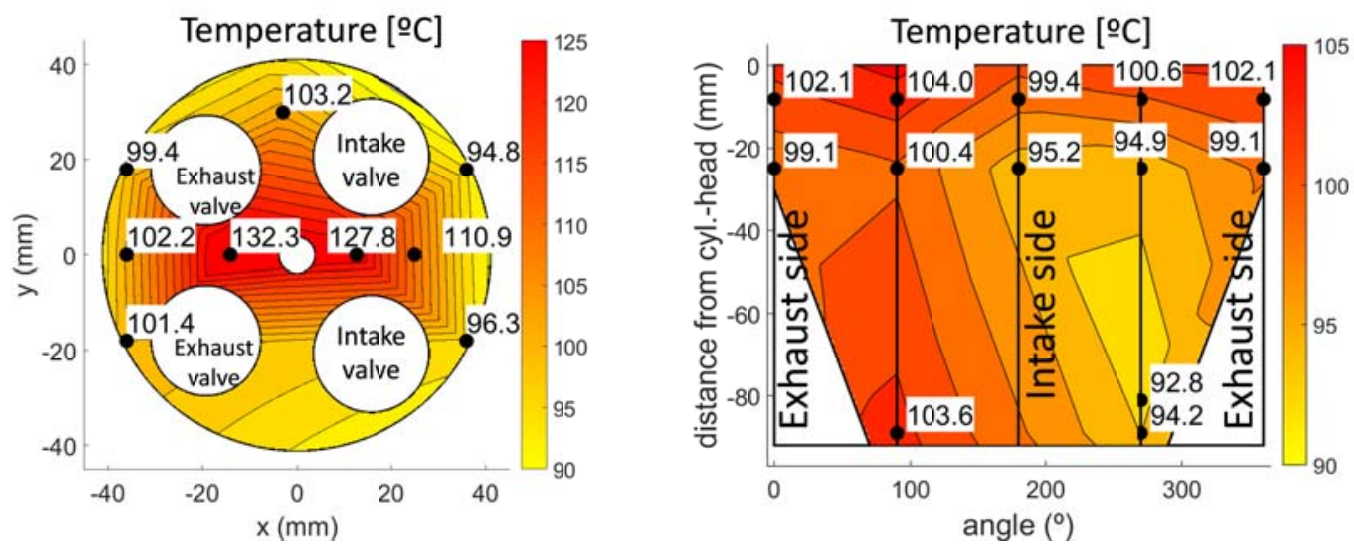

Figure 9. Temperature distribution maps at cylinder head (left) and liner (right)

In Figure 9 left, the temperature distribution at a section of the cylinder head located at 4 mm above combustion chamber can be seen for the 2000@5 k-point at SR=3 (maximum). As observed, the inner part of cylinder head is hotter than the outer area. Besides, as expected, the exhaust side is a bit hotter than the intake side. On the other hand, the complete liner is represented in Figure 9 right at this point. Temperature gradients can be observed in two directions, axial and radial, being the most important the axial one due to the longer contact time of the liner top with the chamber gases.

\section{Single location measurements}

Temperature variation with SR from a single thermocouple in the cylinder head is shown in Figure 10 left. While in Figure 10 right, the temperature difference respect to the minimum SR is presented. In both cases (low and high load) the trend is similar: the higher the SR is the higher the wall temperature is, but the overall increment is lower in the case of lower load $\left(4^{\circ} \mathrm{C}\right.$ versus $\left.8^{\circ} \mathrm{C}\right)$. Temperature increase with $\mathrm{SR}$ can be explained by both the increase of the HT coefficient and the temperatures changes, already discussed. 

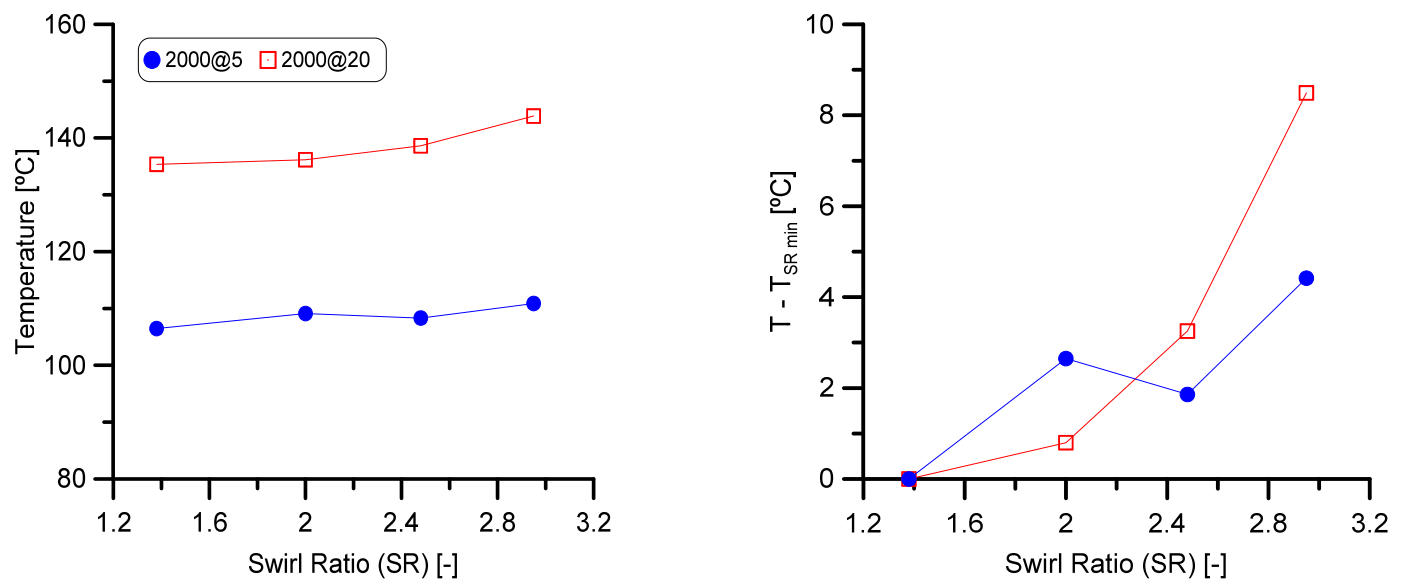

Figure 10. Temperature variation with SR in the cylinder head

In the case of the liner (Figure 11) similar trends are observed, i.e. an increase in temperatures with SR but, as expected, with a lower temperature increment with SR. In this case a temperature increment of approximatively $1^{\circ} \mathrm{C}$ has been observed for the SR variation. This lower temperature variation is explained by the low contact area between the liner and the gas when piston is close to TDC.
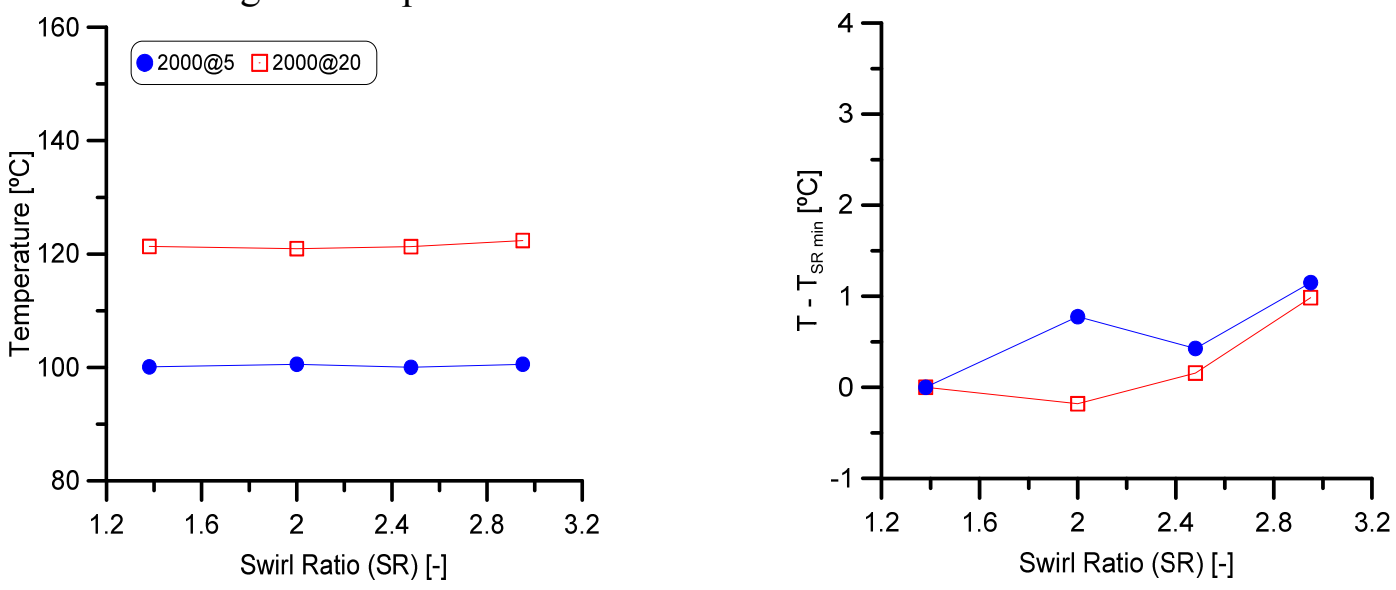

Figure 11. Temperature variation with SR in the liner

Distribution map and local variations

Since the trend of SR on temperatures is similar on all the measured points a comparison map between the obtained temperature maps for the maximum tested SR minus the temperature map for the minimum SR at the same operating point are plotted. Figure 12 shows the effect of SR on a spatial distribution of the temperature in the cylinder head while Figure 13 in the liner. 

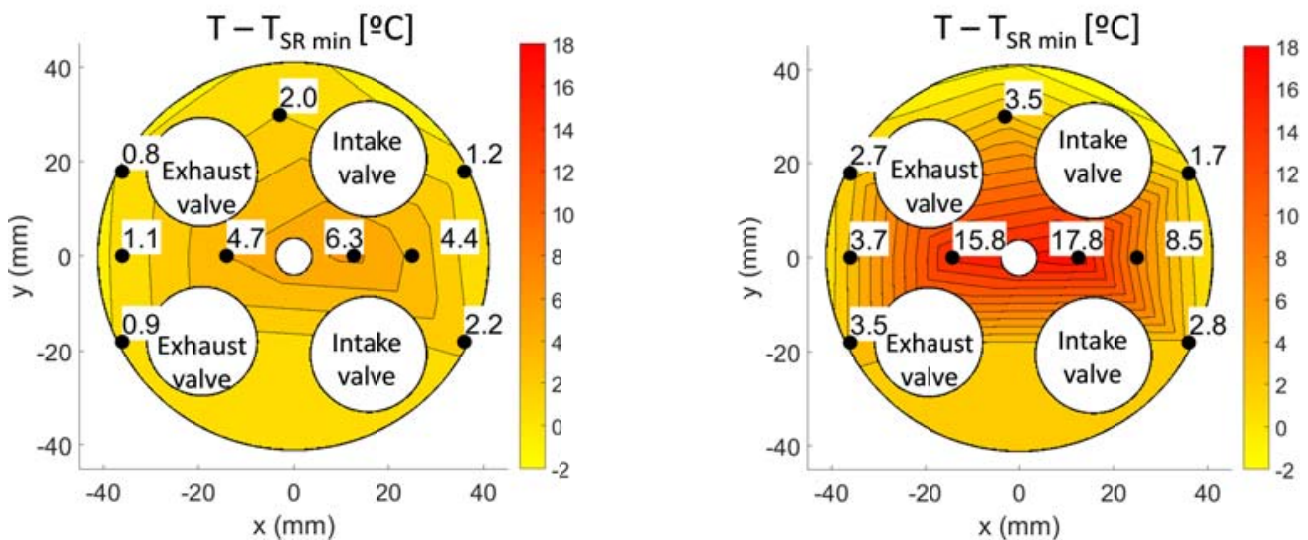

Figure 12. Local variation with SR in the cylinder head at 2000@5 (left) and 2000@20 (right)

From Figure 12 it is clear that swirl induced considerable temperature variations. These variations are more noticeable at the cylinder head center and at the high load point. On one hand, the effect at the center is higher since the thermal gradient seems to be quite radial and, since coolant temperatures were kept constant, the effect of a higher heat flow (that depends on SR) led to higher temperatures on the center. Besides, the load implies a higher gradient on the cylinder head and therefore this effect is magnified with SR.

In the case of the liner, and for the two operating conditions analyzed, the temperature differences with SR shown in Figure 13, are very small and therefore it is difficult to observe clear trends related to location. Only three statements can be made: temperature variations are generally larger on the cylinder top, swirl produces a temperature increase there and both effects are clearer on the higher load point.
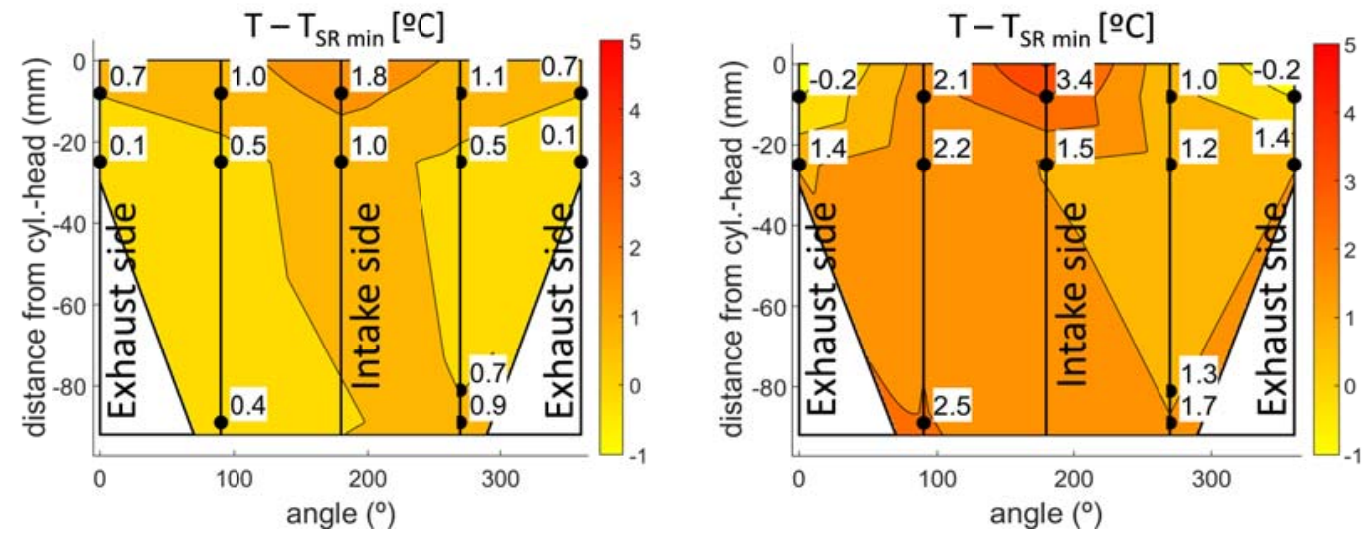

Figure 13. Local temperature variation with SR in the liner at 2000@5 (left) and 2000@20 (right)

\section{Conclusions}

A comprehensive analysis for determining the effect of the swirl ratio on the most important engine parameters has been performed by using both experimental and 
modeled results. These two tools allowed performing a global analysis of the energy flows on the engine by means of a clear methodology. The main conclusions of this work are:

- In general, the higher the SR is, the worse the brake and gross indicated efficiency are. However this trend is not clear at low load and intermediate SR.

- The difference between the observed trends in brake and indicated efficiency have been justified by the pumping losses, which have a key role when SR increases.

- Two main factors that affect engine efficiency have been identified: heat transfer and changes in the RoHR.

- SR increases heat transfer due to higher gas tangential velocity, which leads to a higher heat transfer coefficient. The relative effect is similar in piston, cylinder head, liner and ports, increasing about $1 \%$ of the fuel energy in each of them when SR increases from 1.4 to 3 .

- During the first combustion stage, RoHR was enhanced when swirl increased due to the better mixing promoted by the higher air velocity. However, the maximum combustion rate was affected in different ways depending on load: it increases at low load but decreases at high load.

- Combination of both effects (HT and RoHR effects) led to justify the unclear trend of gross indicated efficiencies at intermediate SR.

- Wall temperatures have been affected due to the effect of SR on HT, i.e. the higher the SR the higher the wall temperatures. This effect is higher at high load.

\section{References}

1. García A, Monsalve-Serrano J, Heuser B, Jakob M, Kremer F, Pischinger S (2015) Influence of fuel properties on fundamental spray characteristics and soot emissions using different tailor-made fuels from biomass. Energy Conversion and Management: vol 108: pp 243-254.

2. Wang, X., Huang, Z., Zhang, W., Kuti, O.A., Nishida, K., "Effects of ultra-high injection pressure and micro-hole nozzle on flame structure and soot formation of impinging diesel spray", Appl. Energ. 88(5), 1620-1628, 2011, doi:10.1016/j.apenergy.2010.11.035.

3. Park, S.H., Yoon, S.H., Lee, C.S. "Effects of multiple-injection strategies on overall spray behavior, combustion, and emissions reduction characteristics of biodiesel fuel”, Appl. Energ. 88(1), 88-98, 2011, doi:10.1016/j.apenergy.2010.07.024.

4. Serrano JR, Olmeda P, Arnau FJ, Dombrovsky A, Smith L (2015) Turbocharger heat transfer and mechanical losses influence in predicting engines performance by using one-dimensional simulation codes. Energy: pp 86: 204-218.

5. Benajes J, Molina S, García A, Monsalve-Serrano J (2015) Effects of low reactivity fuel characteristics and blending ratio on low load RCCI (reactivity controlled compression ignition) performance and emissions in a heavy-duty diesel engine. Energy: vol 90: pp 1261-1271.

6. Ding, Chuan; Roberts, Leighton; Fain, David J.; Ramesh, Aswin K.; Shaver, Gregory M.; McCarthy, James, Jr.; Ruth, Michael; Koeberlein, Edward; Holloway, Eric A.; Nielsen, Douglas. Fuel efficient exhaust thermal management for compression ignition engines during idle via cylinder deactivation and flexible valve actuation. 
INTERNATIONAL JOURNAL OF ENGINE RESEARCH. 17 - 6, pp. 619 - 630. SAGE PUBLICATIONS LTD, 01/08/2016. ISSN 1468-0874, ISSN 2041-3149

7. Jia, Ming; Gingrich, Eric; Wang, Hu; Li, Yaopeng; Ghandhi, Jaal B.; Reitz, Rolf D.Effect of combustion regime on in-cylinder heat transfer in internal combustion engines. INTERNATIONAL JOURNAL OF ENGINE RESEARCH. 17 - 3, pp. 331 346. SAGE PUBLICATIONS LTD, 01/03/2016. ISSN 1468-0874, ISSN 2041-3149

8. Benajes J, Olmeda P, Martín J, Carreño R (2014) A new methodology for uncertainties characterization in combustion diagnosis and thermodynamic modelling. Appl Therm Eng: vol 71: pp 389-399.

9. Torregrosa AJ, Olmeda P, Martín J, Romero C (2011) A Tool for Predicting the Thermal Performance of a Diesel Engine. Heat Transfer Engineering: vol 32 (10): pp $891-904$.

10. Payri F, Olmeda P, Martín J, Carreño R (2014) A New Tool to Perform Global Energy Balances in DI Diesel Engines. SAE Int. J. Engines: vol 7 (1): 2014-01-0665.

11. Payri F, Olmeda P, Martín J, Carreño R (2015) Experimental analysis of the global energy balance in a DI diesel engine. Appl Therm Eng: vol 89: pp 545-557.

12. Payri F, Pastor J, García J Contribution to the application of two-colour imaging to diesel combustion. Meas Sci Technol: vol 18 (8): pp 2579-2598.

13. Payri F, Margot X, Gil A, and Martín J (2005) Computational Study of Heat Transfer to the Walls of a DI Diesel Engine. SAE Technical Paper 2005-01-0210.

14. Payri F, Molina S, Martín J, Armas O (2006) Influence of measurement errors and estimated parameters on combustion diagnosis. Appl Thermal Eng: vol 26(2-3): pp 226-3.

15. Payri F, Olmeda P, Martín J, García A (2011) A complete 0D thermodynamic predictive model for direct injection diesel engines. Appl Energy: vol 88: pp 46324641.

16. Payri F, Galindo J, Martín J, and Arnau F (2007) A Simple Model for Predicting the Trapped Mass in a DI Diesel Engine. SAE Technical Paper 2007-01-0494.

17. Lapuerta M, Armas O, Hernández JJ (1999) Diagnosis of DI Diesel combustion from in-cylinder pressure signal by estimation of mean thermodynamic properties of the gas. Appl Thermal Eng: vol 19(5): pp 513-2

18. McCracken, M. and Abraham, J., Swirl-Spray Interactions in a Diesel Engine (2001) SAE Technical Paper 2001-01-0996.

19. Morena J, Vassallo V, Peterson RC, Gopalakrishan V, Gao J (2014) Influence of Swirl Ratio On Combustion System Performance of a 0.4L Single-Cylinder Diesel Engine. THIESEL 2014 Conference on Thermo-and Fluid Dynamics Processes in Direct Injection Engines.

\section{Acknowledgments}

The support of GM Global R\&D and the Spanish Ministry of Economy and Competitiveness (TRA2013-41348-R) is greatly acknowledged. 